\title{
Fusion esplenogonadal. Presentación de un caso
}

\author{
Trias Puig-Sureda I, Orsola de los Santos A,** Raventós Busquets CX**, \\ Español Quintilla I, Bucar Terrades S*. \\ Servicio de Anatomía Patológica y *Urología . ${ }^{* *}$ Departamento de Urología del Hospital Vall d'Hebrón.
*Clínica Plató Fundació Privada. Barcelona.
}

Actas Urol Esp. 2007;31(5):559-561

\section{RESUMEN}

\section{FUSIÓN ESPLENOGONADAL. PRESENTACIÓN DE UN CASO}

Se presenta un nuevo caso de fusión esplenogonadal en un varón de 27 años. Esta anomalía que resulta la fusión de bazo y gónada a nivel embriológico, se asocia en ocasiones a otras alteraciones congénitas (peromelia). Se presenta con más frecuencia en el escroto izquierdo y aunque descrita en ambos sexos, es diagnosticada con más frecuencia en el sexo masculino. Su importancia clínica radica en que su presentación en forma de tumor suele conducir a la extirpación quirúrgica del mismo. Su reconocimiento a tiempo, (estudio intraoperatorio) puede evitar actuaciones demasiado radicales.

Palabras clave: Ectopia esplénica. Fusión esplenogonadal

\section{ABSTRACT}

SPLENOGONADAL FUSION. REPORT OF A CASE

We present a new case of splenogonadal fusion in a 27 years old male. This anomaly is the result of an embryological fusion between gonad and spleen. Occasionally there is an association with other congenital alterations (peromelia). Usually it occurs in the left scrotum and, although described in both sexes, it is more frequent in males. Its only symptom is palpable tumor and this makes the surgical approach the only way to make the diagnosis. A frozen section study can avoid unnecessary radical surgery.

Keywords: Splenic ectopy. Splenogonadal fusion.

$\mathrm{L}$ a fusión esplenogonadal es una anomalía poco frecuente que suscita interés básicamente porque su presentación como un tumor palpable, provoca la puesta en marcha de todo un armamentarium analítico e iconográfico que suele acabar en quirófano. El conocimiento de su existencia, aunque no impide en la mayoría de los casos la actuación quirúrgica, puede evitar una actitud excesivamente agresiva en algunos $\operatorname{casos}^{1}$.

\section{CASO CLINICO}

Varón de 27 años que acude por presencia de nódulos en hemiescroto izquierdo desde la infancia, que últimamente han crecido.
A la exploración: testículos normales. Nódulos en hemiescroto izquierdo de consistencia similar a los quistes epididimarios, móviles y no dolorosos.

Analitica: Marcadores tumorales negativos. Estudio ecográfico (Fig. 1): dos tumores sólidos en epidídimo izquierdo, con testículo normal. RNM (Fig. 2): Nódulos paraepididimarios izquierdos, bien delimitados que rechazan el epidídimo.

Ante estos hallazgos se decide intervención quirúrgica que demuestra cuatro estructuras nodulares paraepididimarias dependientes de vasos espermáticos e independientes del epidídimo y del parénquima testicular. Se practica exé- 


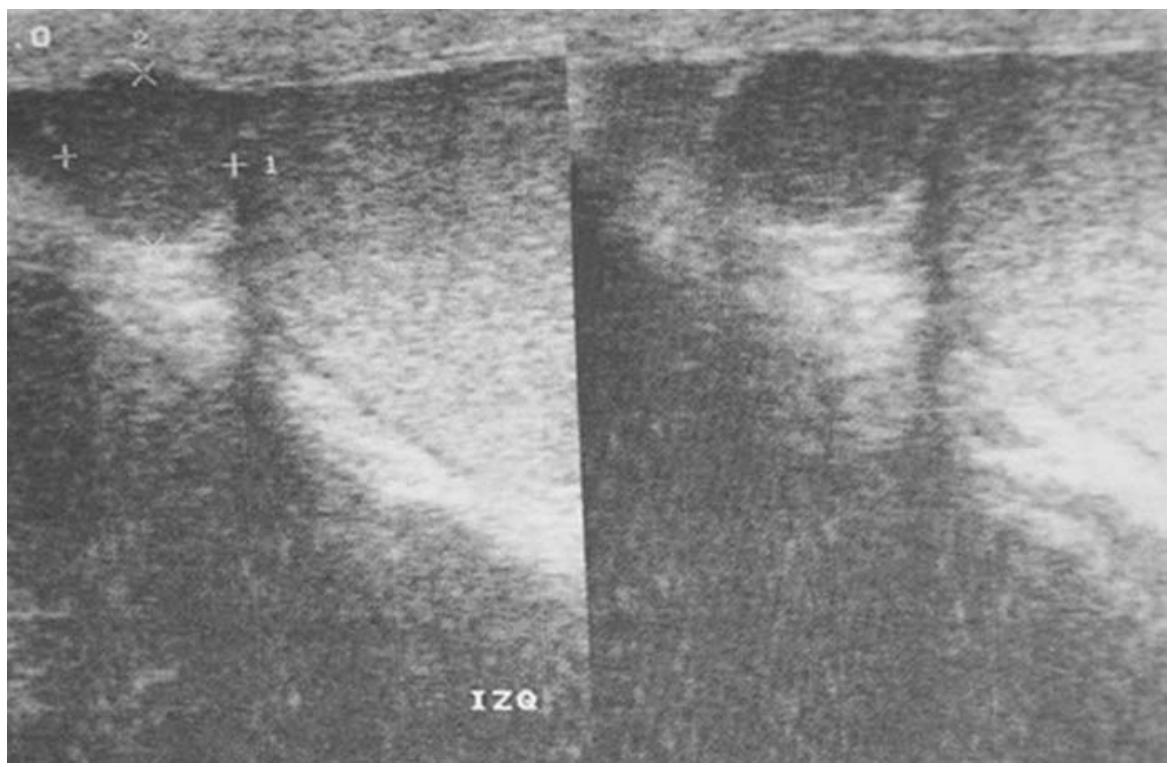

FIGURA 1. Imagen ecográfica

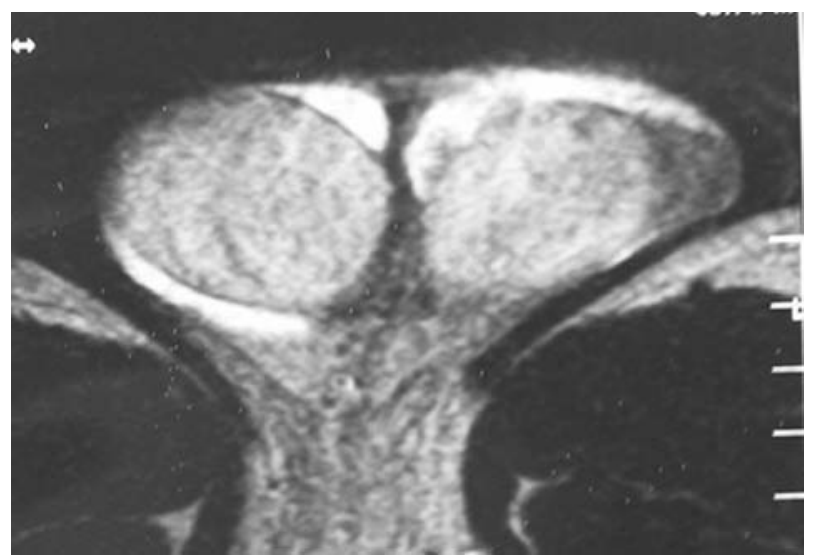

FIGURA 2. Resonancia magnética.

resis de los nódulos (Fig. 3) con estudio intraoperatorio que ratifica la ausencia de malignidad en el material estudiado.

La anatomía patológica definitiva revela la existencia de tejido esplénico maduro, sin alteraciones (Fig. 4).

\section{DISCUSION}

Se conoce como fusión esplenogonadal a la alteración congénita caracterizada por la fusión anómala entre bazo y gónada y derivados del mesonefros. Aunque puede aparecer en los dos sexos, es mucho más frecuente en el masculino (relación de 9 a 1) ${ }^{1,2}$. Existen casos descritos en intersexos ${ }^{3}$.
Se clasifican en dos tipos según su relación con el bazo normal; así se conoce como fusión discontinua cuando no hay ninguna relación anatómica entre el bazo y la gónada, y continúa cuando sí la hay ${ }^{1}$.

Hasta la fecha se han descrito unos $150 \operatorname{casos}^{4}$. Se puede diagnosticar a cualquier edad (1-81 años) y es más frecuente en hemiescroto izquierdo $^{5,6}$.Clínicamente, el 30\% se asocian a malformaciones congénitas que afectan a las extremidades (peromelia) aunque la mayoria se presenta, como en nuestro caso, como nódulos palpables en escroto sin otros síntomas $^{1}$.En contadas ocasiones se ha encontrado asociado a tumor germinal ${ }^{4}$.

El origen de esta alteración se encuentra, como es lógico, en el desarrollo embriológico del bazo y la gónada. Entre la $5^{\underline{a}}$ y la $8^{\underline{a}}$ semana de gestación, las células precursoras de estos órganos se hallan muy próximas.

También están muy cerca las estructuras precursoras de los huesos del hombro lo cual está probablemente relacionado con la asociación a malformaciones en extremidades.

Por algún motivo no se producen una separación total de estos grupos celulares y la gónada

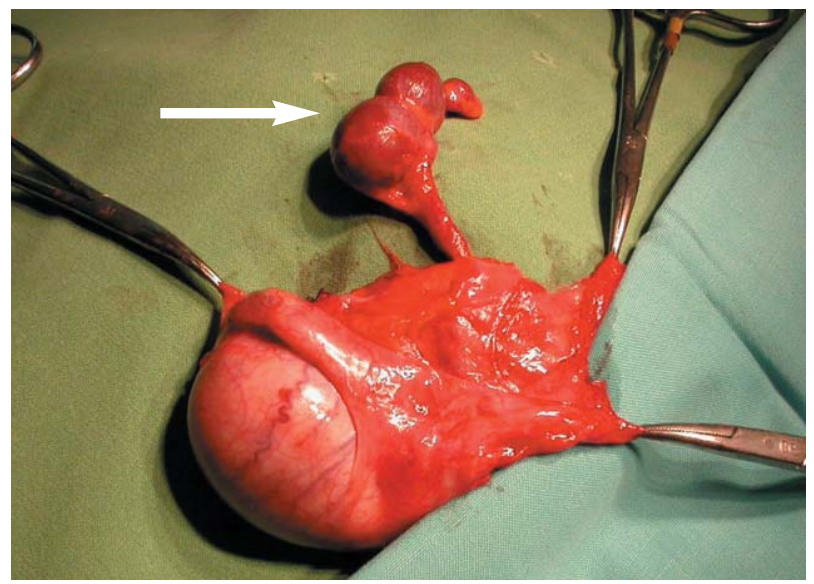

FIGURA 3 . Aspecto macroscópico de la lesión con múltiples nódulos arrosariados (flecha). 


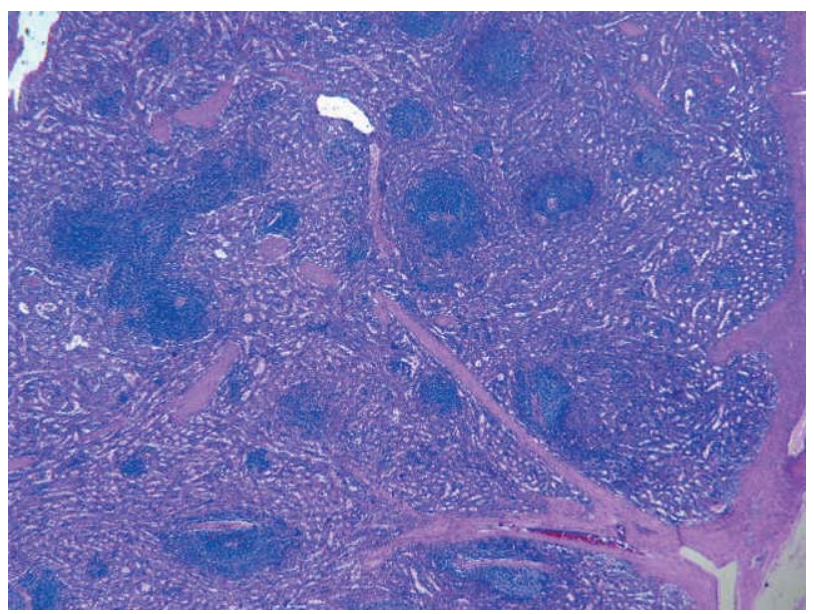

FIGURA 4. Aspecto microscópico de bazo normal (H\&E 4x).

migra junto con restos esplénicos. Este hecho explica que se pueda encontrar tejido esplénico en distintos sitios (a lo largo del cordón espermático, epidídimo o en contacto directo con el parénquima testicular) ${ }^{7}$. El origen embriológico de esta alteración no explica la diferencia de incidencia entre los dos sexos, aunque es posible que los casos en ovario estén infradiagnosticados dado que no pueden ser explorados con la misma facilidad que el testículo por lo que probablemente, si no causan sintomas, no se lleguen a diagnosticar nunca ${ }^{3}$ ). Aunque la existencia de restos esplénicos a nivel del escroto no suele plantear ningún problema, hay que recordar que el bazo, aunque sea ectópico, puede padecer las mismas alteraciones que su homólogo en situación normal. Esto explica algunos casos, excepcionales, de aumentos de tamaño y dolor secundario a enfermedades infecciosas (mononucleosis, paludismo) o neoplásicas (leucemia) ${ }^{7}$.

Aunque la ectopia escrotal esplénica es muy infrecuente, la coexistencia de alteraciones óseas con masa escrotal izquierda asintomática, puede ser motivo de sospecha diagnóstica. En estos casos podrá ser de ayuda el estudio gammagráfico con Tc-998 .

El interés clínico de esta alteración viene dado por el hecho que un diagnóstico intraoperatorio puede evitar una orquiectomía innecesaria, ya que la mera existencia de tejido esplénico normal en el escroto, no constituye ningún tipo de problema para el paciente ${ }^{9}$

\section{REFERENCIAS}

1. Rosai J. en Rosai and Ackerman's Surgical Pathologhy., Chp 22 pg 2021, Editor Rosai J. 9th edition 2004, Ed. Mosby.

2. Gouw AJ, Elema JD, Bink-Boelkens MT, de Jongh HJ, ten Kate LP, The spectrum of splenogonadal fusion. Case report and review of 84 reported cases. Eur J Pediatr. 1985; 144(4): 316-323.

3. Karaman MI, Gonzales ET. Splenogonadal fusion: report of 2 cases and review of the litrerature. J. Urol 1996;155(1): 309-311.

4. Imperial SL, Sidhu JS. Nonseminomatous germ cell tumor arising in splenogonadal fusion. Arch Pathol Lab. Med 2002; 126 (10):1222-1225.

5. Diebold J, Le Blaye O, Le Tourneau A, Marichez P. Intrascrotal supernumerary spleen. A long silent case of discontinuous spleno-gonadal fusion. Ann. Pathol 1990;10 (3):174176.

6. Heimbach D. Wirth M, Muller J, Frohmuller H. Ectopic splenic tissue in connection with testis. Urologe A 1991;30 (2):92-93.

7. Mendez R, Morrow J. Estopic spleen simulating testicular tumor. J Urol. 1969;102:598-601.

8. Virseda JA, Martínez M, Pastor JMaㅗ Cañamares L. Fusión espleno-gonadal: Caso clínico. Actas Urológicas Españolas 1991;15:366-368.

9. Farthouat P, Faucompret S, Debourdeau P, Cruel T, Breda Y. Unusual testicular tumor: an ectopic spleen. Ann Chir. 2001;126(1):67-69.

Correspondencia autora: Dra. I. Trias Ruig-Sureda Anatomia Patológica Clínica Plató Fundació Privada.

Plató 21 - 08006 Barcelona

E-mail: 19612itp@comb.es

Información artículo: Nota clínica

Trabajo recibido: marzo 2006

Trabajo aceptado: septiembre 2006 